\title{
A survey of the indications for early closure of ostium secundum atrial septal defects and subsequent progress of children in whom this has been undertaken
}

\author{
Ruwan Nandana Morawakkorala ${ }^{1}$, James Gnanapragasam ${ }^{2}$
}

Sri Lanka Journal of Child Health, 2012; 41(3): 118-122

\begin{abstract}
Objectives: Closure of isolated secundum atrial septal defect (ASD) is generally recommended at the age of 4 to 5 years. However, there are children with isolated secundum ASDs in whom early closure is performed. The aim of this study is to describe the conditions that led to the decision for early closure and to determine whether these conditions were resolved by means of closure of the defect.
\end{abstract}

Methods: The records of 16 patients who underwent surgical closure of isolated ASD before 24 month of life from 2001 to 2010 at Southampton University Hospital were scrutinised to collect data.

Results: There were eight patients with recurrent respiratory tract infections and failure to thrive, three with only recurrent respiratory tract infection, two with evidence of high pulmonary pressures and one with heart failure. Two patients were asymptomatic but had large defects with significant right sided volume overloading. All patients survived surgery and most of them had an uneventful postoperative period. All patients showed clear improvement of their symptoms during the follow up period. Two patients continued to fail to thrive despite closure of ASD but both had other problems to account for the failure to thrive.

Conclusion: All symptomatic patients with ostium secundum ASD improved following closure of the ASD before two years of age. Co-existing chromosomal or non cardiac anomalies can be associated with a continued tendency to a poor weight gain after ASD closure.

(Key words: Ostium secundum atrial septal defects in infancy; surgical closure)

${ }^{1}$ Fellow in Paediatric Cardiology, Department of Paediatric Cardiology, Southampton University Hospital, United Kingdom, ${ }^{2}$ Consultant Paediatric Cardiologist, United Kingdom

(Received on: Accepted after revision on 25 November 2011)

\section{Introduction}

Atrial septal defect (ASD) is a common congenital heart defect with an incidence of $7 \%{ }^{1}$. Atrial leftto-right shunting is well tolerated in otherwise healthy children. The majority of patients with isolated secundum ASDs remain asymptomatic in infancy and childhood. Usually there is neither pulmonary hypertension nor an increase of pulmonary vascular resistance (PVR) at that age. Typically, closure of isolated ASD is undertaken in the fourth or fifth year of life ${ }^{2}$. Device closure has been used increasingly as an alternative to conventional surgery and such manoeuvres have even surpassed surgical closure in numbers. Nevertheless, catheter closure is technically difficult in infants and small children. However, there is a small group of patients who need to undergo ASD closure much earlier in life. These patients present with severe problems, such as recurrent respiratory infections, failure to thrive, heart failure and respiratory insufficiency necessitating artificial ventilation during infancy.

The aim of this study is to describe the factors that led to the decision to undertake early closure of ASDs and to determine whether these were resolved by means of closure of the defect. Southampton University Hospital NHS Trust (SUHT) provides cardiac services to more than 3 million people in central southern England and the Channel Islands and it was thought to be an appropriate centre in which such a study could be undertaken.

\section{Patients and methods}

The records of all patients who underwent open surgical closure of isolated ASDs before 24 months of life from 2001 to 2010 at Southampton University Hospital were used to collect data. Patients with other co-existing structural heart diseases were excluded from the study. All patients were reviewed at 6 months and 1 year after surgery with regard to improvement of symptoms e.g. heart failure, recurrent respiratory tract infection, failure to thrive etc. The follow up period ranged from 1 to 10 years. 
There were sixteen patients, who were below 2 years of age (mean age 13.1 months and median 14 months) who underwent surgical repair of ostium secundum ASD over the 10 year period from 2001 to 2010. Seven patients were under one year and nine were between one and two years of age. Weights ranged from $4.8 \mathrm{~kg}$ to $10.2 \mathrm{~kg}$ (mean weight $8.2 \mathrm{~kg}$ and median weight $8.7 \mathrm{~kg}$ ). There were five males and eleven females.

\section{Results}

There were eight patients with recurrent respiratory tract infections and failure to thrive, three with recurrent respiratory tract infections without failure to thrive, two had evidence of high pulmonary artery pressure and one had heart failure. Two patients were asymptomatic but had large defects with significant right sided volume overloading. It was thought that these two would not be suitable for device closure and their parents requested early surgical closure.

All patients had cardiomegaly and pulmonary plethora on chest X-ray. Three patients underwent cardiac catheterization before surgery to assess possible additional lesions, pulmonary pressure and Qp (pulmonary blood flow): Qs (systemic blood flow) ratio. All three had Qp:Qs ratio more than 2:1 and pulmonary artery pressures were less than systemic pressures. They showed a reversible pulmonary vascular resistance. Pulmonary arterial pressure was assessed by echocardiography in the other 13 patients and confirmed to be not elevated. Five patients were diagnosed with genetic syndromes of whom two had trisomy 21 , two had $22 \mathrm{q} 11$ deletions and one had Prader-Willi syndrome.

One patient had a right anterolateral mini thoracotomy and all others had standard midline sternotomies. The cardiopulmonary bypass time ranged from 16 minutes to 55 minutes (mean 34 min, median $37.12 \mathrm{~min}$ ) and aortic cross clamp time ranged from 9 minutes to 32 minutes (mean $18.3 \mathrm{~min}$, median $19 \mathrm{~min}$ ). Intra-operatively two patients had fenestrated atrial septal defects. In eleven patients ASD closure was done using an autologous pericardial patch and in one a bovine pericardial patch was used. Direct suture closure of the ASD was carried out in four patients.

All patients survived the operation and most of them had an uneventful postoperative period. One patient had first degree heart block during the first 48 hours after surgery which improved spontaneously. One patient needed temporary pacing for nodal rhythm for less than 24 hours. Postoperative echocardiograms of all patients showed no residual ASDs. One patient had significant pericardial effusion on postoperative day 13. It was successfully drained and there was no recurrence.

One patient with $22 \mathrm{q} 11$ deletion who was preterm (32 weeks, birth weight $1.2 \mathrm{~kg}$ ) and was on home oxygen for chronic lung disease underwent ASD closure at 9 months of age. The indication for ASD closure was poor weight gain, recurrent chest infection and possible worsening of lung disease due to the left to right shunt at atrial level. She had a stormy immediate postoperative course with difficulty in extubation. She was extubated on day 12 and discharged on home oxygen. There was no significant improvement of her weight gain at 6 month and one year follow up but she did not have significant respiratory tract infections. She did not require home oxygen after about 18 months post surgery. At her last follow up (6 years post surgery) she remained small for her age but was otherwise well.

There was a patient with trisomy 21 who did not show an improved weight gain at 6 month and 1 year follow up. All other patents showed normal weight gain during the follow up period. Two patients who had moderately high pulmonary artery pressure did not show evidence of pulmonary hypertensive crises during the early post operative period. They had near normal pulmonary artery pressure at 6 month and 1 year follow up. These patients did not require follow up cardiac catheterization.

Parents of all patients described a clear improvement in their general condition postoperatively. All reported a reduction in number of respiratory tract infections. Echocardiograms showed normalization of right atrial and ventricular size at 6 months follow up.

Patient characteristics and indications for surgery are shown in table 1 . 
Table 1

Patient characteristic and indication for surgery

\begin{tabular}{|l|l|l|l|l|l|}
\hline No & $\begin{array}{l}\text { Age- } \\
\text { months }\end{array}$ & $\begin{array}{l}\text { Weight- } \\
\text { Kg }\end{array}$ & Sex & Extracardiac problems & Indication for surgery \\
\hline $\mathbf{1}$ & 6 & 4.8 & F & Trisomy 21, premature (35) & Pulmonary hypertension \\
\hline $\mathbf{2}$ & 9 & 5.9 & F & $\begin{array}{l}\text { 22q11 deletion, Premature } \\
\text { (32), CLD on home oxygen }\end{array}$ & $\begin{array}{l}\text { Failure to thrive, Recurrent respiratory } \\
\text { tract infections }\end{array}$ \\
\hline $\mathbf{3}$ & 5 & 6.1 & F & $\begin{array}{l}\text { Prader Willi syndrome, } \\
\text { Premature (35), GOR }\end{array}$ & Heart failure \\
\hline $\mathbf{4}$ & 8 & 7.3 & $\mathrm{M}$ & Bronchomalacia & $\begin{array}{l}\text { Failure to thrive, Recurrent respiratory } \\
\text { tract infections }\end{array}$ \\
\hline $\mathbf{5}$ & 10 & 6.9 & $\mathrm{M}$ & Asthma & $\begin{array}{l}\text { Failure to thrive, Recurrent respiratory } \\
\text { tract infections }\end{array}$ \\
\hline $\mathbf{6}$ & 9 & 8.5 & $\mathrm{~F}$ & Premature (34) & Recurrent respiratory tract infections \\
\hline $\mathbf{7}$ & 14 & 7.8 & $\mathrm{~F}$ & Trisomy 21, GOR & $\begin{array}{l}\text { Failure to thrive, Recurrent respiratory } \\
\text { tract infections }\end{array}$ \\
\hline $\mathbf{8}$ & 17 & 9.6 & $\mathrm{~F}$ & - & Parents request \\
\hline $\mathbf{9}$ & 17 & 9.5 & $\mathrm{~F}$ & - & Parents request \\
\hline $\mathbf{1 0}$ & 17 & 9 & $\mathrm{~F}$ & - & Pulmonary hypertension \\
\hline $\mathbf{1 1}$ & 12 & 10 & $\mathrm{M}$ & $22 \mathrm{q} 11$ deletion, Asthma & Recurrent respiratory tract infections \\
\hline $\mathbf{1 2}$ & 23 & 10.2 & $\mathrm{~F}$ & - & $\begin{array}{l}\text { Failure to thrive, Recurrent respiratory } \\
\text { tract infections }\end{array}$ \\
\hline $\mathbf{1 3}$ & 14 & 8.3 & $\mathrm{~F}$ & - & Recurrent respiratory tract infections \\
\hline $\mathbf{1 4}$ & 17 & 8.9 & $\mathrm{M}$ & - & $\begin{array}{l}\text { Failure to thrive, Recurrent respiratory } \\
\text { tract infections }\end{array}$ \\
\hline $\mathbf{1 5}$ & 16 & 9 & $\mathrm{~F}$ & - & $\begin{array}{l}\text { Failure to thrive, Recurrent respiratory } \\
\text { tract infections }\end{array}$ \\
\hline $\mathbf{1 6}$ & 16 & 9.6 & $\mathrm{M}$ & Asthma & $\begin{array}{l}\text { Failure to thrive, Recurrent respiratory } \\
\text { tract infections }\end{array}$ \\
\hline & & & & & \\
\hline
\end{tabular}

CLD-chronic lung disease, GOR-gastro-oesophageal reflux

\section{Discussion}

Patients with ostium secundum ASDs are generally asymptomatic and rarely have problems during childhood. The usual haemodynamic characteristics of an uncomplicated inter-atrial communication are a large left-to-right shunt and normal pulmonary arterial pressure. Despite the greatly increased flow of blood to the lungs, pulmonary arterial pressure is rarely elevated in children and pulmonary vascular resistance is low, frequently less than 1 Wood unit ${ }^{3}$. Although it is uncommon, some children with isolated atrial septal defects do have pulmonary hypertension. On the other hand, there are adults who live into their sixth and seventh decades with markedly increased flow to the lungs who have normal pulmonary vascular resistance and normal pulmonary arterial pressure ${ }^{4}$.

The incidence of symptomatic ASD in infancy varies from 5 percent as reported by Dimich and colleagues to 10 to 13.7 per cent ${ }^{5}$. Symptomatic ASD requiring surgery is even rarer $(3.7 \%)$ at that age ${ }^{6,7}$. It is not clear how these infants differ from asymptomatic ones, although it has been postulated that an atrial septal defect is usually small in infancy and grows to a large enough size to produce symptoms only later in life. While a high incidence of spontaneous closure of ASD in neonates and infants has been reported, others claim that these are only flap-incompetent foramen ovale $^{8}$. These patients are managed medically, allowing sufficient time for spontaneous closure to be observed ${ }^{7,8}$. A few reports mention that ASD may cause congestive heart failure in infancy ${ }^{6,9,10}$. The possible explanations for congestive cardiac failure in infants include a larger than normal leftto-right shunt, the presence of another large left-toright shunt, left-sided obstructive lesions, earlier than usual decreases in pulmonary vascular resistance, abnormal ventricular compliance, and abnormal atrial compliance ${ }^{5}$. Congestive failure can be expected to improve with conservative treatment $^{10-12}$. Spontaneous closure of ASD in cardiac failure and after infancy has also been reported $^{12}$.

It is postulated that early vasodilatation of the pulmonary vascular bed could be the origin of a left-to-right shunt in patients with no increase in pulmonary vascular resistance ${ }^{13}$. Bull and colleagues hypothesized that pulmonary vascular obstructive disease is the primary abnormality in symptomatic infants, ASD being an incidental 
although exacerbating finding, as more than half of the symptomatic children in their series had pulmonary hypertension at cardiac catheterization $^{14}$. Two other reports state similar findings ${ }^{15,16}$.

In our series of patients only two were asymptomatic and all had echocardiographic evidence of large ASDs with right side volume overloading. Surgical closure was the preferred method due to technical difficulties with device closure in patients who are less than two years. As spontaneous closure becomes increasingly uncommon after 2 years of age, the usual recommendation is to correct at any time after this age. There is probably a psychological advantage in accomplishing repair prior to the school years. Earlier intervention is indicated if there is marked cardiomegaly, failure of growth, or congestive heart failure. Although we did not have any mortality in our series of patients' two out of six infants in Bull and colleagues ${ }^{14}$ series died. Significant mortality was noted by Hunt and Lucas in their series where both patients operated on in the first year of life died. This observation partly may be due to improved surgical and post surgical care in the current era ${ }^{6}$.

All patients showed clear improvement of their symptoms during the follow up period. Two patients failed to thrive despite closure of ASD but both had other problems to cause failure to thrive. The experience of Mainwaring and colleagues ${ }^{15}$ with 6 infants who underwent surgical closure of isolated secundum ASD, suggests that failure to thrive associated with this lesion has a noncardiac basis as 5 patients demonstrated little or no improvement in feeding or growth rate following surgery.

\section{Conclusions}

All symptomatic patients with ostium secundum atrial septal defect improved following closure of the ASD before two years of age. Co-existing chromosomal or non cardiac anomalies can be associated with a continued tendency to a poor weight gain after ASD closure. Our survey shows that surgical closure of ASD in symptomatic infants can be carried out without mortality.

\section{Acknowledgment}

Authors wish to thank care group manager for child health, congenital cardiology team at Southampton University Hospital, patients and Dr B J C Perera for his guidance.

\section{References}

1. Hoffmann JIE. Incidence of congenital heart disease. I. Postnatal incidence. Pediatric Cardiology 1995; 16:103-13. http://dx.doi.org/10.1007/BF00801907

2. Chan KC, Godman MJ, Walsh K, Wilson N, Redington A, Gibbs JL. Transcatheter closure of atrial septal defect and inter-atrial communications with a new self expanding nitinol double disc device (Amplatzer septal occluder): multicentre UK experience. Heart 1999; 82:300-6.

3. Nadas AS, Fyler DC. Pediatric Cardiology. Philadelphia, Saunders, 1972. pp 317-34.

4. Nasrallah AT, Hall RJ, Garcia E, et al. Surgical repair of atrial septal defect in patients over 60 years of age: Long term results. Circulation 1976; 53:329-31. http://dx.doi.org/10.1161/01.CIR.53.2.329

5. Dimich I, Steinfeld L, Park SC. Symptomatic atrial septal defects in infants. American Heart Journal 1973; 85:601-4. http://dx.doi.org/10.1016/00028703(73)90164-6

6. Hunt CE, Lucas RV Jr. Symptomatic atrial septal defect in infancy. Circulation 1973; 47:1042-8.

http://dx.doi.org/10.1161/01.CIR.47.5.1042

7. Gordovilla ZG, Cabo SJ, Moreno GP, Alvarez DF. Surgery of symptomatic inter-auricular communication in the first year of life [Spanish]. Anales Espanoles de Pediatria 1988; 29:94-8.

8. Fukazawa M, Fukushige J, Ueda K. Atrial septal defects in neonates with reference to spontaneous closure. American Heart Journal 1988; 116:123-7.

http://dx.doi.org/10.1016/00028703(88)90259-1

9. Joshi NC, Dalvi R, Merchant RH. Symptomatic atrial septal defects in infancy. Indian Pediatrics 1993; 30:1079-83.

10. Wyler F, Rustishauser M. Symptomatic atrial septal defect in the neonate and infant. Helvetica Paediatrica Acta 1976; 30:399-408.

11. Hartmann AF Jr, Elliot LP. Spontaneous physiologic closure of an atrial septal defect after infancy. American Journal of Cardiology 1967; 19:290-2.

http://dx.doi.org/10.1016/00029149(67)90549- 8 
12. Giardina ACV, Raptoulis AS, Engle MA, Levin AR. Spontaneous closure of atrial septal defect with cardiac failure in infancy. Chest 1979; 75:395-7.

http://dx.doi.org/10.1378/chest.75.3.395

13. Suarez CP, Bano RA, Quero JM. Atrial septal defect symptomatic in infancy: report of 11 cases [Spanish]. Anales Espanoles de Pediatria 1977; 10:905-12.

14. Bull C, de Leval M, Stark J, Taylor JF, Macartney FJ. Correction of isolated secundum atrial septal defects in infancy. Archives of Disease in Childhood 1981; 56:784-6.

http://dx.doi.org/10.1136/adc.56.10.784
15. Mainwaring RD, Mirali-Akbar H, Lamberti JJ, Moore JW. Secundum-type atrial septal defects with failure to thrive in the first year of life. Journal of Cardiac Surgery 1996; 11:116-20. http://dx.doi.org/10.1111/j.15408191.1996.tb0 $\underline{0024 . x}$

16. Andrews R, Tulloh R, Magee A, Anderson D. Atrial septal defect with failure to thrive in infancy: hidden pulmonary vascular disease? Pediatric Cardiology 2002; 23:528-30. 